\title{
Imperiale Lebensweise
}

\section{Zur Ausbeutung von Mensch und Natur im globalen Kapitalismus}

\author{
Ulrich Brand, Markus Wissen \\ München 2017: oekom verlag, 224 Seiten.
}

\author{
Andreas Novy \\ Institute for Multi-Level Governance and Development, Wirtschaftsuniversität Wien, Austria \\ E-Mail: andreas.novy@wu.ac.at
}

Ulrich Brand und Markus Wissen liefern mit „Imperiale Lebensweise: Zur Ausbeutung von Mensch und Natur im globalen Kapitalismus" einen lange angekündigten und wichtigen Beitrag zum Verständnis der aktuellen Vielfachkrise, indem sie die materiellen, global organisierten Grundlagen unserer Art zu leben und zu arbeiten sichtbar machen (I3). Aufbauend auf der sozialökologischen Transformationsforschung beschreiben sie „Nichtnachhaltigkeit" als praktischen Sachverhalt, der zumeist unbewusst passiert (48). Handys werden gekauft, ohne den jugendlichen MinenarbeiterInnen im Kongo schaden zu wollen; Fleisch wird konsumiert, ohne zu wollen, dass gentechnikmanipuliertes Soja die fruchtbaren Weiden Südamerikas überzieht. Über den im Supermarkt gekauften Produkten liegt ein Schleier, ihre Produktionsgeschichte, die Ausbeutung von Natur und Mensch, bleibt unsichtbar. Während die meisten Menschen in Westeuropa - was Kaufkraft, aber auch was Lebenserwartung und Bildungsniveau betrifft - heute besser leben als ihre Großeltern, beschleunigt der Aufstieg der Schwellenländer die ökologischen Probleme durch die partielle Verallgemeinerung dieser Lebensweise (I06): Von den 65 Millionen Pkws, die 2015 hergestellt wurden, wurden über 2I Millionen in China produziert (II2).

Brand und Wissen insistieren, dass diese Lebensweise nicht verallgemeinerbar ist und daher unter diesen Bedingungen keine friedliche Lösung des Umgangs mit Ressourcenknappheit möglich ist. Autoritäre und reaktionäre Politikformen sind die Konsequenz. Es scheint, als könnten die herrschenden Produktions- und Konsumnormen nur durch „immer mehr Gewalt, ökologische Zerstörung und menschliches Leid aufrechterhalten" (I6) werden. Damit ist der normative Bezugspunkt ihrer Kritik benannt: eine solidarische Lebensweise, die allen Menschen ein gelungenes Leben ermöglicht, „ohne ihre Voraussetzungen und negativen Folgen zu externalisieren, ohne andere Menschen auszubeuten und ohne ihre eigene Grundlage zu zerstören" (176). Genau dies kann aber die imperiale Lebensweise nicht, weil die Produktions-, Distributions- und Konsumnormen „tief in die politischen, ökonomischen und kulturellen Alltagsstrukturen und -praxen der Bevölkerung im Globalen Norden und zunehmend auch in den Schwellenländern des Globalen Südens eingelassen sind“ (44). So richtig diese ökologische Kritik ist, bleibt unerwähnt, dass die Attraktivität dieser Lebensweise und die Grundlage ihrer fortgesetzten Legitimation auf einem anderen Feld liegt, das scheinbar losgelöst von gesellschaftlichen $\mathrm{Na}$ turverhältnissen ist: den individuellen Freiheitsrechten, deren Wert aktuell durch ihre Demontage in Ländern wie Ungarn, Türkei und Russland wieder besonders offensichtlich wird. Diese Aspekte der westlichen Lebensweise dominieren die öffentliche Diskussion und marginalisieren die ökologische Kritik. Demgegenüber erinnern Brand und Wissen daran, dass diese freiheitliche Lebensweise verwoben ist mit einer neokolonialen Politik, durch die der Globale Norden exzessiv auf die Ressourcen und Reichtümer des Planeten zugreift.

Brand und Wissen legen Mechanismen offen, die Struktur und Handeln, Produktions- und Lebensweise verbinden und zeigen, wie die imperiale Lebensweise materielle Ungleichheiten im Zugang zu Geld und Ressourcen schafft. Die allermeisten Menschen im Globalen Norden sind in diesem Sinne, d.h. global betrachtet, "NutznießerInnen“ (52), denn trotz stagnierender Löhne ist es ihnen mit Hilfe von Billigprodukten und auf Kredit weiterhin möglich, ein materiell gutes Leben zu führen. Auch im Globalen Norden gibt es nämlich Schattensei- 
ten der imperialen Lebensweise, die sich aus Ausgrenzung, zunehmender Ungleichheit, Autoritarismus und fortgesetzter Statuskonkurrenz ergeben. An dieser Stelle wäre es vermutlich hilfreich, Frigga Haugs Überlegungen zu „Frauen: Opfer oder Täter" (Haug 2008: 239-248) weiterzudenken. In den I980er Jahren hat Haug insistiert, dass Frauen nicht bloß Opfer sind, sondern an ihrer eigenen Unterdrückung mitwirken. Gleichermaßen sind die Menschen des Globalen Nordens nicht nur privilegierte Täter, sondern eben auch Opfer einer Wirtschafts- und Sozialordnung, die Konkurrenz und Ausgrenzung begünstigt. Die imperiale Lebensweise ist gleichermaßen "Notwendigkeit und Versprechen, Zwang und Voraussetzung des Lebens sowie der gesellschaftlichen Teilhabe" (56). Diese Überlegungen sollten die abschließenden Politikempfehlungen zur „solidarischen Lebensweise" systematischer leiten. Die Einsicht in die Täter-Opfer-Dialektik führt nämlich zu jener Empathie, die Didier Eribons „Rückkehr nach Reims“" zu so einem Erfolg machte. Und es wäre diese Empathie für die Sorgen der im globalen Maßstab materiell überdurchschnittlich gut gestellten, aber in ihrem Lebensumfeld zunehmend verunsicherten Menschen, die die transformationsorientierte Linke bräuchte, wenn sie es ernst meint mit einem hegemonialen Projekt.

\section{Literatur}

Haug, Frigga (2008): Die Vier-in-einem-Perspektive: Politik von Frauen für eine neue Linke, Hamburg: Argument. 